\title{
Endoscopic anatomy of the approaches to the sellar area and planum sphenoidale
}

\author{
Henrique Faria Ramos ${ }^{1}$, Tatiana Alves Monteiro², \\ Carlos Diógenes Pinheiro Neto ${ }^{1}$, Pedro Paulo Mariani ${ }^{3}$, \\ Felipe Sartor Guimarães Fortes ${ }^{1}$, Luiz Ubirajara Sennes ${ }^{4}$
}

\begin{abstract}
The productive work between otolaryngologists and neurosurgeons has resulted in the emergence of endoscopic endonasal skull base surgery. The goal of the present study is to describe the endoscopic anatomy of the endonasal approach to the sellar region and planum sphenoidale, highlighting the key points of the surgical approach and the neurovascular landmarks. Method: Descriptive study of the endoscopic endonasal dissection of 9 fresh cadavers with exposure of the anatomic structures. Results: The endoscopic endonasal ethmoidectomy and sphenoidotomy allows an expanded access to the sellar area and planum sphenoidale. The surface anatomy of the sphenoid sinus is easily identifiable and provides safe landmarks, guiding the intracranial dissection. Conclusion: The endoscopic endonasal approach to the skull base by the ENT and neurosurgeon is feasible, but it requires adequate anatomical knowledge and endoscopic skills for its realization, which can be obtained by practicing in cadavers.
\end{abstract}

Key words: anatomy, skull base, endoscopic surgery, sphenoid sinus.

\section{Anatomia endoscópica do acesso à região selar e plano esfenoidal}

\section{RESUMO}

O trabalho cooperativo entre otorrinolaringologistas e neurocirurgiões resultou no aprimoramento das técnicas cirúrgicas e no surgimento da cirurgia endoscópica endonasal da base do crânio. O estudo tem como objetivo descrever a anatomia endoscópica do acesso endonasal da região selar e plano esfenoidal, destacando os pontos fundamentais do acesso cirúrgico e referências neuro-vasculares. Método: Estudo descritivo da dissecção endoscópica endonasal de 9 cadáveres frescos com exposição das estruturas anatômicas. Resultados: A etmoidectomia e esfenoidotomia endonasal endoscópica permite um acesso estendido à região selar e plano esfenoidal. A anatomia de superfície do seio esfenoidal é facilmente identificada e fornece pontos de referência seguros, guiando a dissecção intracraniana. Conclusão: $\bigcirc$ acesso endoscópico endonasal para a base do crânio pelo otorrinolaringologista e neurocirurgião é perfeitamente viável, mas para isso o conhecimento anatômico da região e de seus pontos de referência é essencial, o que pode ser obtido pelo treinamento em cadáveres.

Palavras-chave: anatomia, base do crânio, procedimentos cirúrgicos endoscópicos, seio esfenoidal.

\section{Correspondence}

Henrique Faria Ramos

Rua Capote Valente 188 / ap 91

05409-000 São Paulo SP - Brasil

E-mail: henriquefariaramos@terra.com.br

Received 10 May 2010

Received in final form 7 September 2010

Accepted 14 September 2010
Skull base surgery has always been a challenge, due to the complex anatomy of this region, comprising important neuro- vascular structures. Several surgical specialists deal with the treatment of diseases affecting the anterior skull base, such as 
otolaryngologist, head and neck surgeon, ophthalmologist, plastic surgeon, neurosurgeon, among others. The productive work between practitioners, mainly in the fields of otolaryngology and neurosurgery, has resulted in the improvement of the surgical techniques and the emergence of endoscopic endonasal cranial base surgery ${ }^{1}$.

The use of the endoscope for exploration of the sellar contents was first proposed by Guiot, in the $1960 \mathrm{~s}^{2}$. Due to the experience with functional endoscopic sinus surgery, it was an otolaryngologist, Jankowski in 1992, who first reached the sella with the endoscope ${ }^{3}$. However, the exclusively endoscopic approaches to the sellar area gained more popularity in the late 1990s, with the joint work between Carrau, an otolaryngologist, and Jho, neurosurgeon ${ }^{4,5}$.

The nasal cavity can be considered the easiest access to various regions of the anterior skull base. The use of endoscopes allows an effective and safe visualization of the operative field. The continuous advances in diagnostic imaging techniques and the increasing use of stereotactic navigation provided greater accuracy and safety during endonasal procedure. The stereotactic navigation is an useful tool for the surgical guidance while manipulating such a complex anatomic area, especially in cases of reoperation ${ }^{1,6,7}$.

In contrast to traditional craniofacial approaches, the endonasal technique offers a direct access, allowing visualization and manipulation of suprasellar, parasellar and retrosellar and retroclival spaces.

The advantages of endonasal approach are: minimal or no brain retraction, with reduced surgical morbidity and mortality rates; minimization of direct manipulation of visual structures and preservation of its vascularization, therefore, resulting in lower rates of visual impairment in the postoperative period; early and precise identification of the pituitary gland and its stalk, assisting in the preservation of endocrine function?

A difficulty regarding the expanded endonasal approaches is the reconstruction of the resulting defect, especially when there are major dural flaws, associated with high rates of CSF leaks in the postoperative period. However, the use of pedicle flaps for endoscopic reconstruction of the skull base reduced this rate drastically. Currently the rate of CSF leak from endonasal approaches is similar to the ones in traditional craniofacial approaches ${ }^{8}$.

In-depth knowledge of the endoscopic anatomy of the skull base is essential for the safe conduct of surgical procedures in this region. The aim of this study is to describe the endoscopic anatomy of the endonasal approach to the sellar area and planum sphenoidale, highlighting the key points of the surgical approach and neurovascular landmarks.

\section{METHOD}

Descriptive anatomical study of the endonasal dissection of 9 fresh cadavers, with no former preservation or vascular injections. The dissections were performed at the São Paulo City Morgue, and were held on four hands by an otolaryngologist and a neurosurgeon. The former carried out the approach to the sellar area and planum sphenoidale and the handling of the endoscope, and the latter the intracranial dissection. Telescopes Karl Storz Hopkins $\mathrm{II}^{\circ}$, with $4 \mathrm{~mm}$ in diameter and $18 \mathrm{~cm}$ long, with $0^{\circ}$ and $45^{\circ}$ lenses, were used to achieve the dissection. The endoscope was connected by a fibreoptic cable to a 24 watt HiLux high performance cold light source and the endoscopic images were viewed and documented in the Tele Pack $^{\odot}$ System from Karl Storz and stored in a 64 MB PCMCIA memory card.

\section{RESULTS}

\section{Sellar area}

The endonasal approach to the sellar area requires the creation of a wider surgical access to allow the exposure and manipulation of different structures of this region.

The endoscope is introduced through the right nasal floor, allowing the identification of the inferior and middle turbinates and the nasal septum. With the progression of the endoscope through the nasal fossa, the choana, which is the lower anatomical landmark, is identified. The medial margin of the choana is formed by the vomer, which guides the position of the midline of the approach. The roof of the choana is composed by the floor of the sphenoid sinus and laterally, we find the tail of the inferior turbinate. By the rostral angulation of the endoscope, along the roof of the choana, the ostium of the sphenoid sinus is identified in the sphenoethmoidal recess, which is usually about $1.5 \mathrm{~cm}$ above the bow of the choana.

First, an anterior ethmoidectomy is accomplished, with removal of the uncinate process and ethmoid bulla (Fig 1A). A lot of care is required during this step to avoid injury of the anterior ethmoidal artery, a branch of the ophthalmic artery that courses within a thin layer on the roof of the ethmoid sinus. Then, a posterior ethmoidectomy is performed exposing the anterior wall of the sphenoid sinus and skull base. Held at the sequence, a transethmoidal sphenoidotomy is executed, always in a medial and inferior direction to avoid injury to important structures located in the posterolateral wall of the sphenoid sinus (Fig 1B).

With the introduction of the endoscope inside the sphenoid sinus, the bony prominences of the internal carotid artery (ICA) and optic nerve (ON) are identified, and between them the optic-carotid recess (OCR), which may extend into the cranial fossa as the pneumatization of the anterior clinoid process (Fig 1C). 


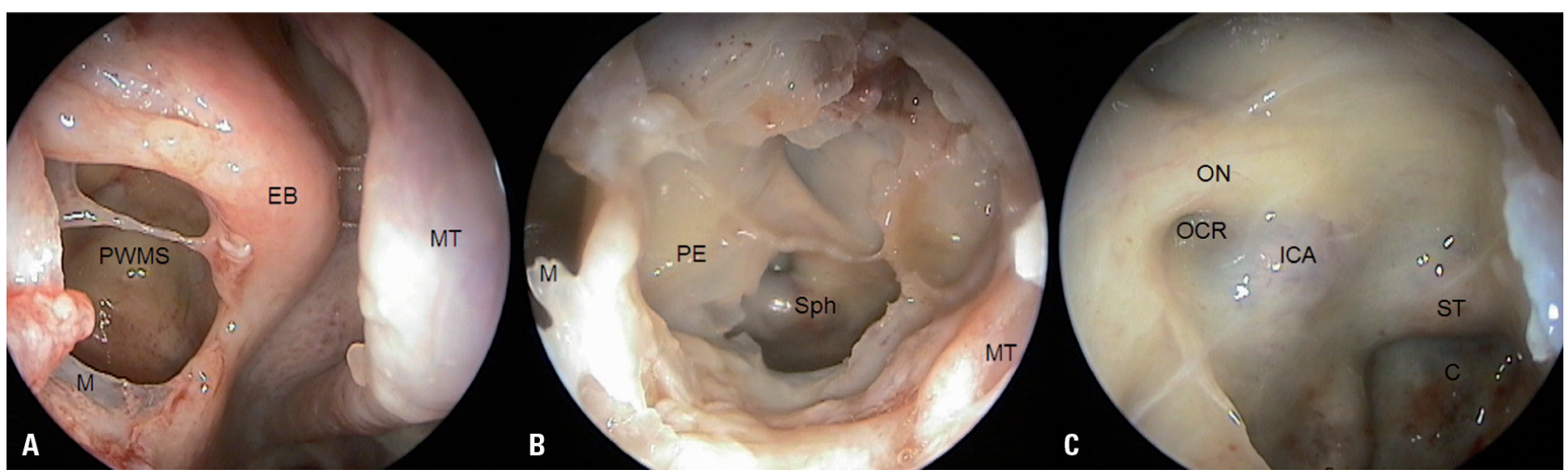

Fig 1. [A] Endoscopic view of the right nasal cavity with $0^{\circ}$ telescope after the removal of the uncinate process and opening of the ethmoidal bulla (EB). The maxillary antrostomy (M), posterior wall of the maxillary sinus (PWMS) and middle turbinate can be observed. [B] Transethmoidal approach to the sphenoid sinus (Sph), labeled the maxillary antrostomy (M), middle turbinate (MT) and posterior ethmoid (PE). [C] Structures on the posterolateral wall in the sphenoid sinus: optic nerve (ON), proeminence of the internal carotid artery (ICA), optic-carotid recess (OCR), sella turcica (ST) and clivus (C).

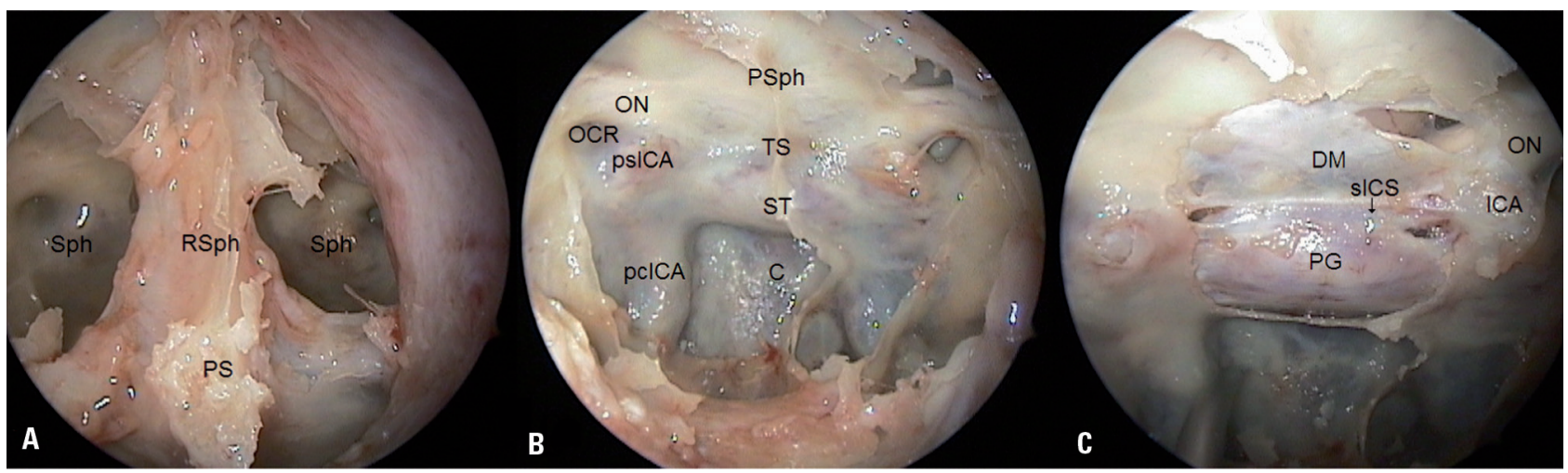

Fig 2. [A] Visualization of both sphenoid sinuses (Sph) and the rostrum of the sphenoid sinus (RSph), after the removal of the posterior nasal septum (PS). [B] Following the removal of the rostrum of the sphenoid sinus and the intersinusal septum an expanded approach to the sphenoid sinus is accomplished, with identification of the planum sphenoidale (PSph), tubercullum of the sella turcica (TS), floor of the sella turcica (ST), optic nerve (ON), parasellar internal carotid artery (psICA), optic-carotid recess (OCR), paraclival internal carotid artery (pclCA) and clival recess (C). [C] Removal of the bone overlying the anterior wall and floor of the sella turcica, tubercullum of the sella and the posterior portion of the planum sphenoidale. (PG) pituitary gland covered by the dura-mater of the sellar floor, (DM) duramater, (sICS) superior intercavernous sinus.

In order to obtain a wide surgical field, the middle turbinate is removed on one side (usually the right) and outfractured on the other side.

After the identification of the sphenoid sinus ostium bilaterally, the upper posterior portion of the nasal septum is resected, along with the rostrum of the sphenoid, taking down the entire anterior wall of this sinus (Fig 2A). The sphenoidotomy is enlarged in an inferior and medial direction to avoid damage of the posterior septal artery, located laterally.

Following the expanded anterior sphenoidotomy, the intersinus septum is resected, allowing visualization of the posterior and lateral walls of the sinus, the bulge of the sella in the midline, the planum sphenoidale superiorly and the clivus indentation inferiorly (Fig 2B).

\section{Planum sphenoidale}

The planum sphenoidale is limited laterally by the bulge of the optic nerve that courses toward the orbital apex. The approach to the planum sphenoidale begins by removing the tubercullum of the sella up to the opticcarotid recess. It is important to drill, using a diamond burr, all the bone of the planum sphenoidale and sella turcica until achievement of a thin bone sheet. Only after that, the surgeon should begin to remove the bone of that region. The anterior half of the floor of the sella and the posterior portion of the planum sphenoidale are removed first, isolating the tubercullum. Then, the thin tubercullum is carefully removed and dissected from the dura, avoiding damage to the superior intercavernous sinus. The removal of the tubercullum and/or planum 


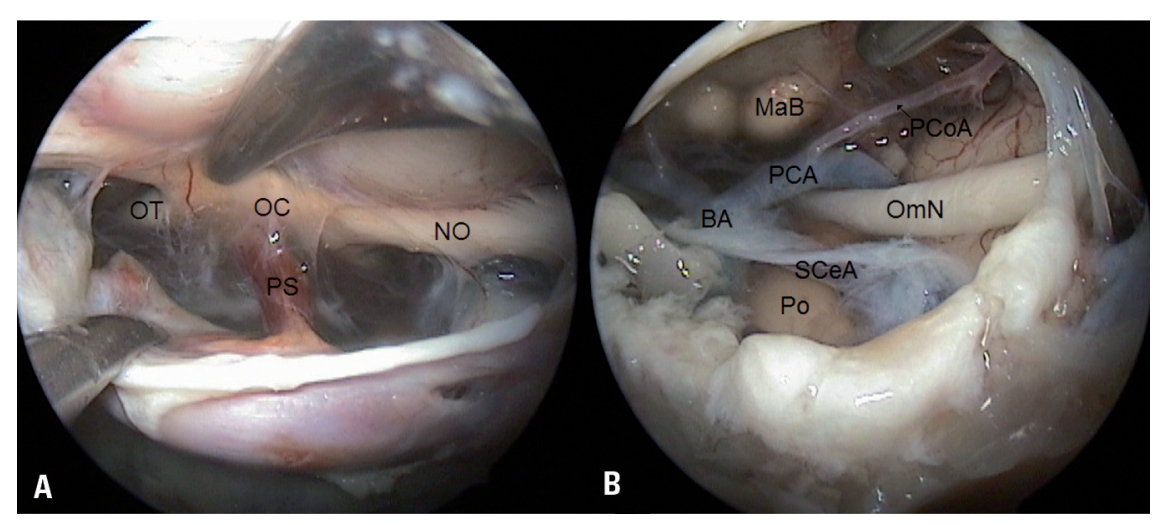

Fig 3. [A] Opening of the dura-mater overlying the pituitary gland with identification of the optic nerve (ON) and optic chiasm (OC), optic tract (OT) and pituitary stalk (PS). [B] After the superior displacement of the pituitary gland and removal of the dorsum of the sella, the mammillary bodies (MaB), basilar artery $(B A)$, posterior cerebral artery (PCA), posterior communicating artery ( $\mathrm{PCOA}$ ), oculomotor nerve $(\mathrm{OmN})$, superior cerebellar artery (SCeA) and pons (Po) are visible.

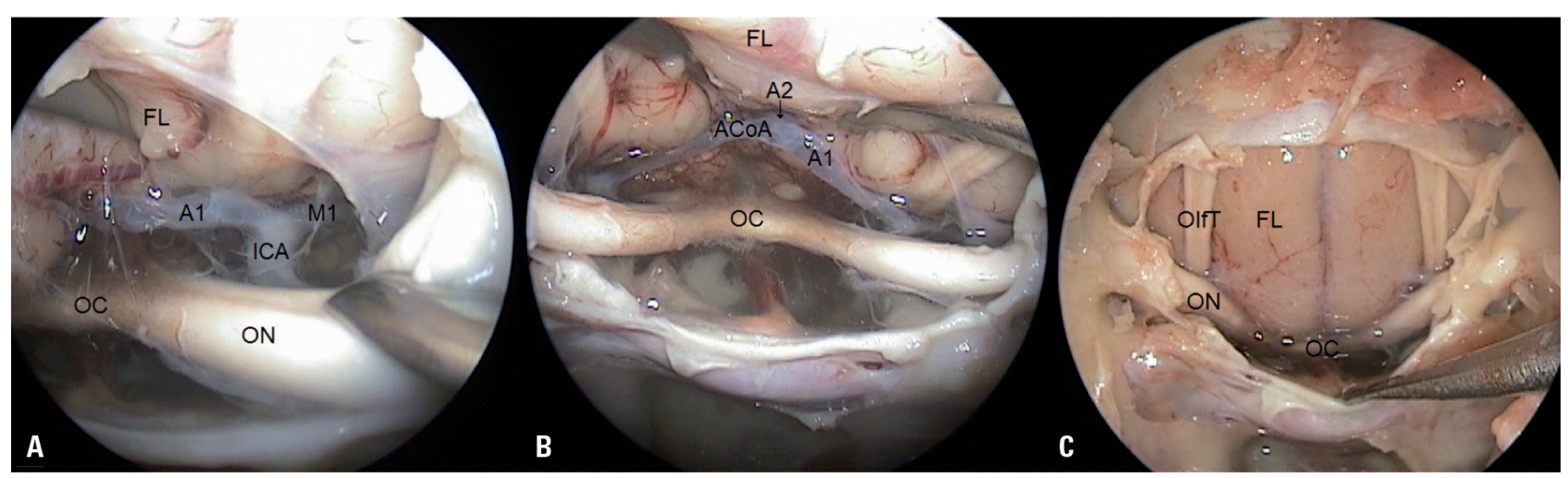

Fig 4. $[A]$ The inferior shift of the optic nerve $(\mathrm{ON})$ and chiasm (OC), the internal carotid artery (ICA), pre-communicating segment of the anterior cerebral artery (A1) and a portion of the sphenoidal segment of the middle cerebral artery (M1) are visible. [B] Endoscopic view with a $45^{\circ}$ telescope of the anterior communicating artery (ACOA) and post-communicating segment of the anterior cerebral artery (A2) after de outward deviation of the frontal lobes (FL). [C] The removal of the upper half of the posterior nasal septum and bone overlying the anterior skull base exposes the basal surface of the frontal lobe (FL) and olfactory tracts (OlfT), located anteriorly to the optic nerve $(\mathrm{ON})$ and chiasm (OC).

sphenoidale is extended toward anteriorly by 1.5 to 2 $\mathrm{cm}$, but not beyond the posterior ethmoidal artery. The bony protrusions of the optic nerve represent the lateral aspect of the dissection (Fig 2C).

The dura overlying the pituitary gland (subjacent to the tubercullum of the sella) is opened, allowing the visualization of the intracranial structures. The optic nerve and chiasm are clearly identified. At this point, two accesses can be considered, one above and one below the chiasm.

Below the chiasm, the pituitary stalk and gland with its vascularization are visible. The progression of the endoscope between the pituitary stalk and the supraclinoid portion of the ICA, allows the exposure of the ventral surface of the chiasm and optic tract (Fig 3A).

After the superior displacement of the pituitary gland and removal of the dorsum of the sella, it is possible to reach the posterior fossa and expose the ventral portion of the pons and mesencephalum. The mammillary bodies, posterior cerebral artery and superior cerebellar artery, with the III cranial nerve between them, are visible (Fig 3B).
Following the inferior shifting of the optic nerve, one can visualize the bifurcation of the internal carotid artery, the anterior cerebral artery and the initial portion of the middle cerebral artery (Fig 4A). Positioning an angled endoscope above the chiasm, after the outward deviation of the medial surfaces of the frontal lobes, exposes the anterior portion of the circle of Willis, with identification of the anterior communicating artery (Fig 4B).

\section{Approach to olfactory tract}

At this point, the upper half of the posterior nasal septum is removed. Bilateral anterior and posterior ethmoidectomy, removal of the middle turbinate bilaterally and bilateral sphenoidotomy should be performed to allow complete visualization of the entire anterior skull base.

The bone of the anterior skull base between the orbits (planum sphenoidale) is removed and the dura opened, therefore allowing access to the intra-cranial components.

The olfactory tracts and the basal surface of the frontal lobe (gyrus rectus) can be visualized (Fig 4C). 


\section{DISCUSSION}

The midline skull base is commonly divided into three parts: [1] anterior skull base, from the roof of nasal cavity (crista galli and cribriform plate of the ethmoid bone) to the planum sphenoidale; [2] middle skull base, which is formed by the body of the sphenoid bone, tubercullum of the sella, pituitary fossa, anterior and posterior clinoid processes, the carotid sulcus, and the dorsum of the sella; and [3] posterior skull base, which extends from the dorsum of the sella to the anterior border of the foramen magnum ${ }^{7,9}$.

According to Cavallo et al. ${ }^{7}$, the extended endoscopic endonasal approaches offer the possibility of exposing the entire midline skull base from below, with the advantage of passing through a less delicate structure (nasal cavity) to reach a more noble one (the brain with its neurovascular structures).

The sphenoidal sinus is strategically located in the center of the midline skull base, therefore the majority of the endoscopic endonasal approaches encompass this aerated nasal cavity. For this reason, its degree of pneumatization is an important factor regarding these procedures, since the greater the pneumatization, the easier it is to identify the bony protuberances and depressions inside this sinus and to access surroundings structures and regions ${ }^{10-12}$. In addition to that, more anterior portions of the skull base are reached with a different trajectory, through the anterior and posterior ethmoidal cells.

Knowledge of the surface anatomy of the sphenoidal sinus and ethmoidal cells is essential to the successful achievement of skull base approaches. The prominences of the sella, optic nerve and carotid artery are easily identifiable in well pneumatized sinuses and provide safe landmarks. The carotid artery and optic nerve protuberances mark the lateral aspect of the dissection, since cranial nerves are located more laterally in the cavernous sinus and are somewhat protected by them ${ }^{13}$.

However, the sphenoid sinus is extremely variable in size and degree of pneumatization, for this reason hallmarks of the lateral wall of the sphenoid sinus may be salient, barely noticeable or absent. Elwany ${ }^{14}$ observed the bony impressions of the carotid artery and optic nerve in, $42.7 \%$ and $29 \%$, respectively. Whereas Saaren ${ }^{10}$ did not find any bulge of the optic nerve in any of the studied sinuses, even the ones with postsellar pneumatization, suggesting the possibility of racial variation.

The endoscopes provide exceptional magnification and illumination of the surgical field ${ }^{13}$, as well as direct access to the suprasellar, parasellar and retrosellar and retroclival areas under direct visual control ${ }^{6}$. However, the major principle in achieving the best outcomes is the collaborative surgery between otolaryngologists and neurosurgeons. Preferably by an otolaryngologist with experience performing functional endoscopic sinus surgery and a neurosurgeon with experience performing transsphenoidal pituitary and transcranial cranial base surgery ${ }^{1}$. Several teams of surgeons are facing complex pathologies, such as CSF leaks, craniopharyngiomas, tubercullum sellae meningiomas, macroadenomas involving the cavernous sinus, upper clival chordomas by the means of an endoscopic transsphenoidal approach ${ }^{6}$.

In the present study we reviewed the endoscopic endonasal anatomy of the sellar area and planum sphenoidale in order to systematize the dissection of this region with emphasis on identification of the surface anatomy and key anatomic landmarks. The achievement of the endoscopic endonasal approaches to the skull base by the otolaryngologist and neurosurgeon is perfectly feasible; but for this matter, the anatomical knowledge of the region and its reference points is essential.

Anatomical variations were not considered in the performed dissections. However, new dissections are necessary to establish the frequency of possible anatomical variations and measures between the reference points.

The joint training by the otolaryngologist and neurosurgeon in cadavers is important for the acquisition of anatomical knowledge and interplay of both on the fourhand technique.

\section{REFERENCES}

1. Schwartz TH, Fraser JF, Brown S, Tabaee A, Kacker A, Anand VK. Endoscopic cranial base surgery: classification of operative approaches. Neurosurgery 2008;62:991-1005.

2. Guiot G, Rougerie J, Fourestier M, et al. Intracranial endoscopic explorations. Presse Med 1963;71:1225-1228.

3. Jankowski R, Auque J, Simon C, Marchal JC, Hepner H, Wayoff M. Endoscopic pituitary tumor surgery. Laryngoscope 1992;102:198-202.

4. Jho HD, Carrau RL. Endoscopic endonasal transsphenoidal surgery: experience with 50 patients. J Neurosurgery 1997;87:44-51.

5. Grosvenor AE, Laws ER. The evolution of extracranial approaches to the pituitary and anterior skull base. Pituitary 2008;11:337-345.

6. Cappabianca P, Cavallo LM, de Divitiis O, Solari D, Esposito F, Colao A. Endoscopic pituitary surgery. Pituitary 2008;11:385-390.

7. Cavallo LM, Messina A, Cappabianca P, et al. Endoscopic endonasal surgery of the midline skull base: anatomical study and clinical considerations. Neurosurg Focus 2005;19:1-14.

8. Hadad G, Bassagasteguy L, Carrau RL, et al. A novel reconstructive technique after endoscopic expanded endonasal approaches: vascular pedicle nasoseptal flap. Laryngoscope 2006;116:1882-1886.

9. Rhoton AL Jr. The supratentorial cranial space: microsurgical anatomy. Neurosurgery 2002;51(Suppl 1):S273-S302.

10. Sareen D, Agarwal AK, Kaul JM, Sethi A. Study of sphenoid sinus anatomy in relation to endoscopic surgery. Int J Morphol 2005;23:261-266.

11. Cavallo LM, de Divitiis O, Aydin S, et al. Extended endoscopic endonasa transsphenoidal approach to the suprasellar area: anatomic considerations - Part 1. Neurosurgery 2007;61:24-34.

12. Wang J, Bidari S, Inoue $K$, Yang H, Albert Rhoton AL Jr. Extensions of the sphenoid sinus: a new classification. Neurosurgery 2010;66:797-816.

13. Bassim MK, Senior BA. Endoscopic anatomy of the parasellar region. Am J Rhinol 2007;21:27-31.

14. Elwany S, Elsaeid I, Thabet H. Endoscopic anatomy of the sphenoid sinus J Laryngol Otol 1999;113:122-126. 